\title{
The Periodicity of Violent and Property Crime in Tshwane, South Africa
}

\section{Authors:}

Ellen G. Cohn, Ph.D.

Department of Criminal Justice

Florida International University

PCA 261A

Miami, FL 33199

Tel: 305-348-5846

E-mail: cohne@fiu.edu

Gregory D. Breetzke, Ph.D.

Faculty of Natural and Agricultural Sciences

Department of Geography, Geoinformatics, and Meteorology

University of Pretoria

Tel: +27124204318

E-mail: greg.breetzke@up.ac.za

\begin{abstract}
In this paper we identify and analyse the periodicity of violent and property crimes committed in Tshwane, South Africa from 2001 to 2006. Fourier analysis is used to identify periodic moments in time at which the risk of being a victim of violent and property crime in the city is heightened. Results indicated that violent crime peaks roughly every 7 and 75 days over the five year study period, with a marginal peak every 150 days. Property crimes peak every 75 days and every 150 days. Periodic peaks of crime observed in this study are explained using the central tenets of routine activities theory. Fourier analysis is an underused, powerful data-driven mathematical tool that should be added to the methodological arsenal available to criminologists when analysing the temporal dimension of crime.
\end{abstract}

Keywords: periodicity, South Africa, Fourier analysis, violent and property crime 


\section{Introduction}

The notion that crime has periodicity or is cyclic in nature is not new. As early as the nineteenth century, Quételet (1969) observed that crime has a seasonal periodicity. He found that crimes against property reached a maximum in winter, and crimes against the person peaked in the summer months. His findings were later supported by Sutherland (1947) who also found that property crimes reached their highest levels in winter, while crimes against the person peaked in the hot days of summer. Since then, however, research into the seasonality of crime has produced somewhat inconsistent results, with some researchers finding support for Quetelet's summer increase in property crimes (see e.g., Anderson, 1987; Cohn \& Rotton, 2000), while others finding peaks during winter (see e.g., Field, 1992; Landau \& Fridman, 1993; Van Koppen \& Jansen, 1999). In terms of violent crime, several researchers have found no seasonal effect (see, e.g., Cheatwood, 1988; Hipp, Bauer, Curran, $\&$ Bollen, 2004) while others have found statistically significant seasonal patterns (see e.g., Hakko, 2000; Hird \& Ruparel, 2007).

Research into weekly and daily variations of crime has tended to provide more consistent and significant findings. Results of this work have largely demonstrated that crime as a whole peaks on weekends and dips during the middle of the week (LeBeau, 1994; LeBeau \& Corcoran, 1990). Not surprisingly however, different types of crimes display different weekly variations. For example Morrison and O'Donnell (1994) and van Koppen and Jansen (1999) found Fridays to be the most popular days for commercial property crime in England and the Netherlands respectively, while violent crimes such as rape, assault and homicide have been found to be more common on Saturdays (Jewkes \& Abrahams, 2002; Ceccato, 2005). Of course, crime is also distributed unevenly during the course of a day. While this fact is generally acknowledged by criminologists, the area itself is under-researched. This is largely due to a lack of indicators summarizing hour-of-day variations in crime, although some measures have been introduced to address this (Felson \& Polsen, 2003). Most types of crimes typically peak during the evening and late night/early morning hours and fall to a low later in the morning (see e.g., Pittman \& Handy, 1964; Pokorny, 1965; Feldman \& Jarmon, 1979; Henry \& Bryan, 2000; Ceccato, 2005). These temporal variations in crime are most likely explained by the opportunities or risks that are present as people vary their activities depending on the temporal resolution. For example, property crime most often occurs during 
the day as people are often at work or out conducting daily errands leaving their homes unoccupied and easy targets for potential offenders.

While most prior research has shown the temporal variability of crime, these studies have either identified temporal patterns of crime at various hypothesized resolutions (i.e., by season, day or hour); or attempted to explain these variations empirically. In contrast, in this study we adopt a more inductive, data-driven methodological approach in an attempt to identify previously unknown and/or unpredictable periodic peaks of crime. As a result we do not test any previously stated hypotheses but rather let the explorative technique generate results which we attempt to explain using our existing knowledge of the geographic locale under investigation. In doing so, this study moves beyond the extant criminological literature on temporal analysis of crime in three important ways. First, Fourier analysis is used as a mathematical tool in the temporal examination of crime data. While Fourier analysis has been previously used in a variety of physical sciences, the use of this technique in criminology is relatively new and novel. In fact, we are aware of only a handful of studies that have applied this technique to crime data (Tranter, 1985; Rhodes, Kling, \& Johnston, 2007; Biermann et al., 2009) and none have employed it in the way that this study proposes. Second, the results of this research may provide important insight into existing criminological theory by offering a unique perspective of the temporal variability of crime in a study area. By placing time as a key ingredient in criminological research we expand upon the theoretical developments of earlier researchers, such as Rengert and Wasilchick (1985), Miller (2005), and Ratcliffe (2006). Third, by examining criminal variations in Tshwane, South Africa, this research adds an important international perspective to the existing temporal crime research. Most of the research of this nature has been conducted in the United States and Europe; very little is known about the temporal variations in criminal behavior in less developed contexts, particularly in Africa.

In this paper we first outline a key criminological theory that offers an explanation for temporal patterns of criminal behavior. We then describe the crime data employed and outline the methods used in this research. Finally, we present the results and discuss their theoretical implications 


\section{Theory}

A criminological theory that is extremely adept at interpreting and understanding periodicities of crime is routine activities (RA) theory (Cohen \& Felson, 2006). Unlike the vast majority of criminological theories, which tend to focus on offender characteristics, RA theory emphasizes the importance of examining characteristics of crimes. It focuses on offender opportunity and victimization risk rather than on offender motivation and argues that crime can only happen when there is a convergence in space and time of three essential elements: a motivated offender, a suitable target and the lack of a capable guardian. The availability of each of these three elements varies over time, affecting the likelihood that they will co-occur and thus impacting the possibility of criminal events and criminal victimization.

RA theory suggests that individuals generally follow fairly strict and regimented routines - daily, weekly, monthly or seasonal, and even yearly routines (Brunsdon, Corcoran, Higgs, \& Ware, 2009). Essentially, the same periodicities that are found throughout nature and in society as a whole also exist in individual human behavior. Some of these individual 'routine activities' are essentially obligatory, such as attendance at school or work. These tend to be fairly fixed in duration across time periods and rarely change. However, other activities, such as social events, are more discretionary and less fixed in time; individuals have more choice as to if and when they will engage in these activities (Lebeau \& Corcoran, 1990). The theory suggests that during those periods when individuals are not engaged in normal routine activities, the likelihood of convergence of the three key elements increases, affecting opportunities for victimization and crime.

RA theory is often used to explain well-known temporal variations and fluctuations in the occurrence of crime. Ratcliffe (2006) has stressed the effect of time as a constraint on offender movement and behavior, particularly in relation to obligatory rather than discretionary activities. Essentially, he argues that those activities that do not place strong temporal constraints on individuals are less likely to inhibit offender motivation. For example, as noted earlier, it is generally accepted that rates of violent crime tend to be higher on weekends than on weekdays; this appears to be due at least in part to variations in routine activities. During the week, people tend to be more involved with obligatory routine activities, leaving less free time for crime (and possibly reducing offender motivation), while on the weekends the increased amount of free time provides more opportunity for crime and victimization (Rotton \& Cohn, 2000). Similarly, public and school holidays, which are of 
course periodic in nature, have been linked to variations in the occurrence of crime (Cohn \& Rotton, 2003) and may help to not only explain the seasonal periodicity of crime but also why seasonal patterns of crime have been found to vary by geographic location, particularly country.

Another factor that may impact crime periodicities are periodic events that are location-specific and which may serve as crime (Brantingham \& Brantingham, 1995). Crime generators are settings or events that draw in large numbers of people for non-criminal reasons; this has the effect of bringing offenders and targets together and creating opportunities for crime. Festivals and sporting events are good examples of crime generators. The local nature of these events means that they may only affect crime rates in those locations; as a result, crime periodicities are likely to vary by country, city, and even neighborhood. It is important to realize that because these crime generators are locationspecific, the results of any analysis will be impacted by how the data are stratified. Minor periodicities that occur in smaller areas may be masked by overall community patterns.

\section{Methods}

\section{Data}

Crime data for this study were obtained from the former Crime Information Analysis Center (CIAC) of the South African Police Services (SAPS). The SAPS group serious crime committed in South Africa into five broad categories: contact crime (crimes against the person); contact-related crime; property-related crime; other serious crime; and crime detected as a result of police action. Detailed descriptions of the crime categories are provided in South African Police Services (2014). The CIAC provided crime data for Tshwane across all five categories from September 1, 2001 to August 31, 2006 (5 years). Included in the data were the location (x-y co-ordinates), date, and time of day, as well as a unique code for each crime incident. The five categories of serious crime provided by the SAPS were re-categorized into violent and property crime. Violent crime in this research consisted of murder, attempted murder, rape, assault with intent to cause grievous bodily harm, common and indecent assault. Property crimes included all burglary, theft, and robbery. We are weary of summing crime into these two broad categories. The dangers of aggregating crime across various types are well-known (see Andresen \& Linning, 2012), 
however this study was mainly interested in identifying unique periodicities of violent and property crime, broadly speaking. It was also an aim of ours to improve the statistical power of the analysis by making the two crime categories as voluminous as possible. Future research could disaggregate crime further in order to make more specific interpretations about what is driving the periodicities of certain crime types, if indeed any are found.

Finally, it is worth noting that crime data obtained from the SAPS must be viewed with caution (Gould, Burger, \& Newham, 2012). Although a worldwide phenomenon, the underreporting of crime in a South African context cannot be underestimated. Victim surveys in South Africa consistently uncover between $60 \%$ and $70 \%$ more crime than reported by official sources, with upwards of $50 \%$ of crime in many serious categories being unreported (see Statistics South Africa, 2011). Victims of crime in South Africa, particularly in more deprived neighbourhoods, are often reluctant to report crime to the SAPS due to a general mistrust in the criminal justice system that stems in part from their experiences under apartheid (see Kynoch, 2003; Breetzke, 2012). While there may be more malevolent reasons for the under-recording of crime the truth is that it is near impossible to report and record all crime over a given period. Despite this however previous international research has shown that using official police data usually produces results consistent with victimisation surveys (see Byrne \& Sampson, 1986; McDowall \& Loftin, 1992; Ceccato \& Dolmen, 2011) and a number of local researchers have successfully used SAPS data in a variety of crime contexts (see Breetzke, \& Cohn, 2012; Breetzke \& Cohn, 2013). In any event, official records from the SAPS represent the only official and spatially replete crime dataset available in the country. Whilst it is possible that examining case dockets or using police call-for-service data might provide a better measure of crime activity over this period, this information is currently unavailable in South Africa. Therefore, whilst the crime data obtained may not be fully representative of the exact number of crime occurring within Tshwane over the study period, it is the most reliable and comprehensive dataset available for the researchers to examine.

\section{Analytical Analysis}

The first step in the analytical process was the programming of a database in which every record corresponded to an hour in the day (from September 1, 2001 to August 31, 2006). The total numbers of violent and property crimes committed within each of the 43829 hours over this five year time period were calculated (total crime $=648,254$; violent crime $=159,621$; property crime $=488,634)$ and added to the database. Fourier analysis was then used to 
identify periodic time sequences at which the risk of being a victim of violent and/or property crime in Tshwane was heightened. Fourier analysis is one of the most pervasive tools in applied analysis and is typically employed to detect the presence of a frequency or periodicity in a large dataset. In its narrowest sense, Fourier analysis provides an accurate and economical description of a time-series dataset, although the term is also used more broadly to describe any data analysis procedure that measures fluctuations in a time-series by comparing them with sinusoids (Bloomfield, 2004). From a more technical perspective, the technique involves the decomposition of a time-series dataset into a sum of sinusoidal components (the coefficients of which are the discrete Fourier transform of the series). The result of the analysis is a description in (sine or cosine) cycles of different length, which generates that sequence (Bloomfield, 2004). In contrast with similar models such as the autoregressive integrated moving average (ARIMA) or exponential smoothing, the purpose of Fourier analysis is to identify the seasonal fluctuations of different lengths. In the former types of analysis, the length of the seasonal component is usually known (or guessed) a priori and then included in some theoretical model of moving averages or autocorrelations. Fourier analysis on the other hand yields a description in sine or cosine cycles of differing length, which generates that sequence. For additional theoretical information on the use of this technique see Tolstov (1976) and Stein and Shakarchi (2003).

The history of Fourier analysis stretches back to the early Greek and Egyptian astronomers who observed the periodic motion of the sun sufficiently well enough to know that the length of the year was 365.25 days (Bloomfield, 2004). Throughout the $19^{\text {th }}$ century more sophisticated versions and techniques of Fourier analysis were developed to use over a series of numbers (Whittaker \& Robinson, 1924). Fourier analysis is most commonly used in the physical sciences (chemistry, geophysics, climatology) where the technique has been historically used to test the stability of time-dependent finite-difference formulae (LeVeque $\&$ Trefethen, 1988). We do however note the increasing use of the technique in the related discipline of forensic science where Fourier analysis has been used to, among others, determine the time of death of victims of crime (Smart, 2010), provide an estimation for the age of blood stains (Edelman, Manti, van Ruth, van Leeuwen, \& Aalders, 2012), and enhance fingerprint feature extractions (Chikkerur, Cartwright, \& Govindaraju, 2007). 


\section{Results}

Figure 1 shows the periodicities identified by the analysis for both violent and property crimes in Tshwane. It is important to note that the numbers on the Y-axis are not the linear days of the year but rather represent day periods. As a result the values on the Y-axis represent all possible days during which there could be periodicities in violent and property crimes. Thus, for example, the violent crime peak at the 7-9 day time period identifies a periodicity that occurs on approximately a weekly basis (i.e., every 7-9 days); it does not indicate a rise in crime on a particular date or day of the week, but rather that over the five years of the study there is a 'peak' of violent crime every 7-9 days in Tshwane. The nonspecificity of the peak could be an indication of the temporal accuracy of the crime data used, or more likely, the fact that the weekend spans two days. The lengths of the peaks (X-axis) indicate their magnitude of occurrence in percentage. For example, approximately $4.5 \%(n=$ 7,182 ) of all violent crime over this five-year time period is committed every 7-9 days. In summary, there is a periodic peak in violent crime every 7-9 days in Tshwane; over the whole five year study period approximately $4.5 \%$ of violent crime has occurred at this periodicity. The next highest periodic peak for violent crime is found at the 75-80 day time period, followed by less moderate peaks at the 21 day and 145 day periods. There is an additional discernible peak at 365-370 days which is not shown on this graph due to space restrictions. This was the only other notable peak in violent crime.

For property crimes, the greatest periodicity is found at roughly the 75-78 day time period; that is, approximately $4.7 \%(n=22966)$ of all property crime committed over this five-year time period occurs every 75-78 days. There is a second peak, of lesser magnitude, at approximately the 155 day period and other notable peaks every 7-8 days, every 18-20 days, and every 64-66 days. As with violent crime, there is also an additional discernible peak at 365-370 days, representing an annual periodicity of crime, which is not shown on this graph. 


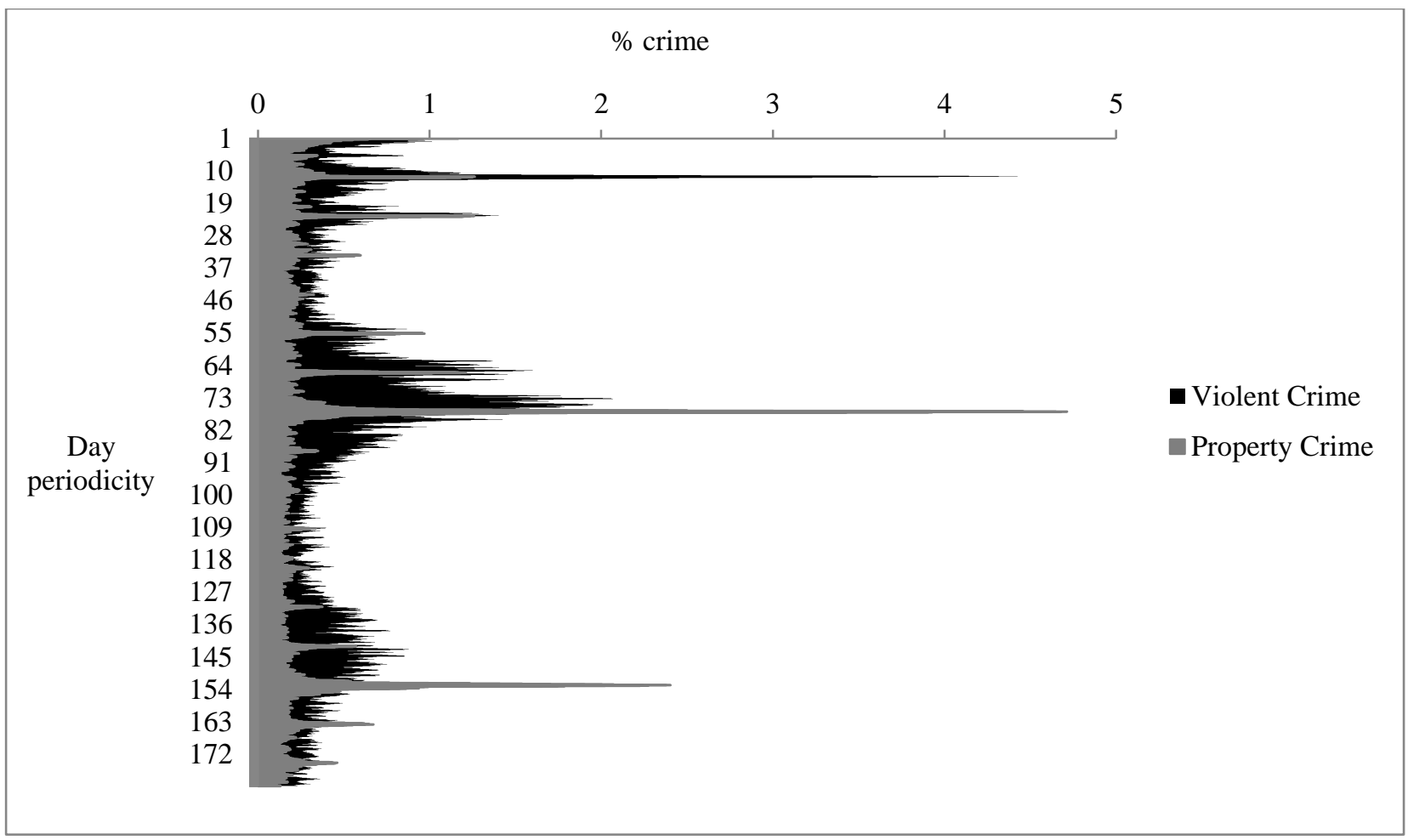

Figure 1: Fourier analysis of violent and property crimes in Tshwane (2001-2006)

\section{Discussion}

One challenge when adopting a data-driven approach to temporal crime analysis is attempting to make sense of the specific observations made. In the sections below, we attempt to explain these results within the framework of RA theory and provide some initial thoughts on implications of these results for this theory.

\section{Violent Crime Periodicities}

For violent crime, the largest periodicity observed in the data (by a substantial distance) occurred weekly (i.e., every 7-9 days). This is not surprising as it is fairly well accepted that violent crime follows a weekly cycle, with more violent crime on the weekends than on weekdays. Of course, a weekend occurs every seven days, resulting in the peak observed. A number of other short-term economic variations, such as weekly paydays, may also contribute to this cycle. In South Africa, a large number of unskilled migrant labourers are paid weekly, which would result in an increase in cash on hand for these segments of the 
population that have previously been shown to be at a greater risk of offending in South Africa (Breetzke \& Horn, 2006). Additionally, a number of small loans firms in South Africa also deliver a weekly pay day system to benefit financially constrained individuals. It could be that this convergence of weekly income through paydays and/or loans coupled with the occurrence of weekends may explain this crime peak occurring every 7-9 days over the five year study period.

Violent crime also exhibits a second periodicity falling roughly between the two and three-month time period. The explanation for this observation is less obvious but it may be related to the occurrence of school holidays in the country. School calendars in South Africa are generally broken up into four terms of approximately three months each. Each term is followed by two or more weeks of vacation when schools are closed. Previous research both in the United States (Cohn \& Rotton, 2000) and China (Peng, Xueming, Hongyong, \& Dengsheng, 2011) has demonstrated an increase in crime during periods of school closings and holidays. This appears consistent with RA theory as the occurrence of school holidays can result in changes in routine or typical activities of people, thus increasing the probability that individuals will be vulnerable to certain types of criminal victimization or will be motivated to engage in crime. School holidays in particular may change the type of behaviors in which individuals choose to engage, such as socializing more frequently with friends or going away on vacation; these clearly may affect the likelihood of certain types of violent crime by increasing the amount of time they spend in social contact with others. School holidays also may be times when family and friends spend more time together; this may increase the risk of violent crimes such as assault, which frequently involve victims and offenders who know each other in some way (Cohn \& Rotton, 2003).

More moderate peaks for violent crime are found at approximately three-week intervals and at an almost five-month interval. It is not certain as to the causes of these periodicities; they may be related to sporting events, national and/or local holidays, or other local events that act as crime generators. Last, the peak found at the 365-70 day period may be explained by major public holidays and/or events that occur annually such as New Year's Day, Christmas, or any major sporting event or activity that occurs periodically on the same day each year. 


\section{Property Crime Periodicities}

The largest periodicity for property crimes observed in the data occurred approximately every two and a half months. This is similar to that exhibited in the violent crime data, although the property crime peak is much sharper and more pronounced. Again, this may be related to the occurrence of school holidays which typically exhibits a two and a half month cycle in South Africa.

A second smaller peak occurs approximately every five months. Similar to violent crime, this may be associated with holidays or local events; it also could possibly be linked to repeat victimization. Research into property crime victims generally has found that one predictor of property crime victimization is prior victimization; having a prior burglary event, for example, appears to increase the risk of a future burglary (Johnson, 2008; Sidebottom, 2012). While the majority of the research suggests that the risk of repeat victimization tends to be highest shortly after the initial crime occurred and then declines fairly rapidly, a number of studies have found an additional increase in risk well after the decline, particularly for nonresidential burglaries. For example, Weisel (2005) found that commercial burglars used a 'cool down' period, waiting until the victims had reduced their vigilance before targeting the same location again about five months after the original crime. Similar increases in victimization roughly four to five months after the initial burglary have been found in Canada (Polvi, Looman, Humphries, \& Pease, 1990), the United Kingdom (Chenery, Holt, \& Pease, 1997), and Australia (Townsley, Homel, \& Chaseling, 2000). This may be related to economic factors as well; offenders are aware that victims are likely to replace many stolen items after receiving insurance money and they may delay revictimisation until these replacement items will be available as targets. The peak found at the 365-70 day period for property crime could be explained by the occurrence of major public holidays, events or activities that occur periodically on the same day each year.

Finally, it is important to note that Fourier analysis is a data-driven technique that robustly determines the periodicity of phenomena. In our context, we envisage it as an inductive approach to analysing crime data that does not, and cannot, accept or reject a null hypothesis. The technique allows the data to drive the process and generate descriptive results which need to be explained post hoc using existing knowledge; and/or tested further using additional techniques. For example, the explanation provided here that school holidays could account for the periodicities observed for both violent and property crime can be readily 
tested using existing additional time-series techniques. If an association is found, then the explanation has potential validity; if no association is found, then there would appear to be another activity or process driving this association. Therein lies the strength of Fourier analysis in identifying potential known (or speculated) and unknown periodicities in crime or some periodic phenomena. Results generated can then be explained and/or undergo further analysis. We do not purport to have all the answers here and there are potentially other more relevant explanations to explain the patterns we have observed in our study but we suggest that uncovering them requires additional analysis which is beyond the scope of this work. Future research in this area could aim to investigate the explanations we have provided for the observed violent and property crime periodicities in this study perhaps using more conventional statistical approaches.

\section{Theoretical Implications}

The findings of this research have important theoretical implications for RA theory and also help to identify areas in which future research is needed. First, it is clear that studies of crime periodicities have focused primarily on attempting to explain previously identified temporal variations in crime. Little effort has been made to identify any additional unidentified periodicities that may be hidden or otherwise unpredictable. A greater focus on examining "unknown" temporal variations in crime data, and on time as a significant variable within criminology, may expand our understanding of RA theory considerably. Second, the vast majority of existing research into temporal variations in crime has been carried out in the United States, with some studies conducted in Europe and Asia; temporal based studies in other parts of the globe are extremely rare. Expanding the focus to include South Africa allows for a greater understanding of the generalizability of RA theory to less developed areas and to areas with markedly different cultural perspectives and ethnocentricities. The explanations provided for the periodicities identified in both violent and property crime not only provide support for RA theory's contention that changes in routine activities affect the likelihood of criminal victimization but also suggest that RA theory may be applicable to studies of criminal behaviour in other parts of the world, particularly in South Africa.

However, the identification of previously undiscovered cyclical periodicities in crime in Tshwane suggests that there may be additional currently unknown context-specific routine 
activities that serve as crime generators and/or crime attractors in the city. The challenge is to identify what these periodic activities may be. Future research might attempt to determine whether these newly-identified temporal variations are location-specific or if they occur in countries other than South Africa. Expansion of this research to additional settings outside South Africa may also help to increase our understanding of the possible links between RA theory and other criminological theories such as social disorganization (Shaw \& McKay, 1942). Future research could also attempt to examine crime periodicities at finer spatial scales (e.g., examining individual neighbourhood periodicities rather than a city as a whole) and using finer temporal scales (e.g., identifying hourly periodic peaks of crime) than those used here.

\section{Limitations}

There are several limitations in this study. The first is a problem that is very common in research of this nature: that of determining the exact time at which a criminal incident occurs. This is particularly relevant in the case of property crime. This problem presents a challenge for all temporal crime researchers since victims may be away at the time of the offense or the property crime may occur at some point during the night. The SAPS typically record a burglary event at the time the incident is reported to the police. While other ways of predicting the actual time of property crime was committed are available (Ratcliffe, 2010), these methods often require an estimated 'start' and 'end' date/time that the victim was away from his/her residence. This level of detail is not captured by the SAPS. For violent crime, however, both the offender and the victim are present at the time of the offense; and in some instances the assault may be witnessed by law enforcement officers or someone willing to contact the authorities, or the crime is detected by closed circuit television system (CCTV). We therefore accept that the property crime data provided could be more prone to temporal accuracy errors than the violent crime data. However we believe that this issue is minimised in the present study because the temporal resolution used in this research is the day rather than the hour the crime occurred.

Second, it is probable that different periodicities exist in violent and property crime in different parts of the city, particularly if there are local crime generators (such as local festivals or other events) that affect individual neighborhoods but have little impact on the city as a whole. Stratifying neighborhoods within a city by various socio-demographic factors might produce different and more insightful periodicities in crime. Future research is needed 
to examine the inter-and intra-neighborhood temporal variation of crime using the same methodology employed here. This is an avenue for future research.

Third, we would like to have conducted this research over a much longer time period (i.e., crime between 2001-2014). This would have given greater statistical power to the technique employed and may have resulted in stronger 'peaks' of periodicity or uncovered other instances of high periodicity across both crime types. However, crime data from 2007 were however unavailable. Regardless, the five years' worth of crime data, detailing approximately 650,000 incidences of crime, are more than adequate in identifying unique periodicities in crime trends.

Finally, this study is based in one city in South Africa; it is almost certain that applying this tool to other countries would produce different periodicities if only because each country (or even each city within a country) may have different periodic events that affect crime. Therefore, the generalizability of the specific results found in this study to cities in other parts of the world is open to debate. However, the method of studying temporal variations of crime introduced here clearly may be used in other settings and may increase our understanding of the similarities and differences in criminal offending worldwide.

\section{Conclusion}

This research has identified cyclical periodicities of crime in a city over time. While the data-driven approach adopted here has its limitations, we believe nonetheless that the results generated have extremely important implications for criminology. First, the study has shown that Fourier analysis is an underused but clearly viable tool for studying temporal variations in time-series crime data. This study represents one of the first exploratory attempts at using this tool; additional research is needed to both refine how it is used and expand the possibilities for its continued application in the discipline. Second, the study has identified several periodicities that have not previously been explicated in earlier research. It is possible that the explanations provided for these periodicities at those time periods are not supported in future research; and that it is still yet to be determined what causes these peaks. We believe this uncertainty is a strength of the use of Fourier analysis and of this study, rather than a drawback. Third, we have conducted this research in South Africa, allowing for international comparisons of temporal variations in crime and criminal behavior. This research is intended 
to employ a relatively new tool for examining temporal variations in crime data; clearly much future research is needed to determine its cross-national viability and to refine its use. However, we believe that this paper represents a good first empirical and exploratory step in a potential new and exciting direction in the temporal analysis of crime data.

\section{References}

Andresen, M. A. \& Linning, S. J. (2012). The (in)appropriateness of aggregating across crime types. Applied Geography, 35, 275-282.

Anderson, C. (1987). Temperature and aggression: effects on quarterly, yearly, and city rates of violent and non-violent crime. Journal of Personality and Social Psychology, 52, 11611173.

Biermann, T.,Asemann, R., McAuliffe, C., Ströbel, A., Keller, J., Sperling, W., Bleich, S., Kornhuber, J., \& Reulbach, U. (2009). Relationship between lunar phases and serious crimes of battery: A population-based study. Comprehensive Psychiatry, 50, 573-577.

Bloomfield, P. (2004). Fourier analysis of time series: an introduction, $2^{\text {nd }}$ edition. New York: John Wiley.

Brantingham, P. L. \& Brantingham, P. J. (1995) Criminality of place: crime generators and crime attractors. European Journal on Criminal Policy and Research, 3, 5-26.

Breetzke, G. D. (2012). Understanding the nature of crime in post-apartheid South Africa. Social Identities: Journal for the Study of Race, Nation, and Culture, 18, 1-17.

Breetzke, G. D. \& Cohn, E. G. (2012) Seasonal assault and neighborhood deprivation in South Africa: Some preliminary findings. Environment \& Behavior, 44, 641-667.

Breetzke, G. D. \& Cohn, E. G. (2013) Burglary in gated communities: An empirical analysis using routine activities theory, International Criminal Justice Review, 23, 55-73.

Breetzke, G. D. \& Horn, A. C. (2006) Crossing the racial divide: A spatial-ecological perspective of offenders in the City of Pretoria Metropolitan Municipality, South Africa. GeoJournal, 67, 181-194. 
Brunsdon, C., Corcoran, J., Higgs, G., \& Ware, A. (2009) The influence of weather on local geographical patterns of police calls for service. Environment and Planning B: Planning and Design, 36, 906-926.

Byrne, J. M., \& Sampson, R. J. (1986) Key issues in the social ecology of crime.

In J. M. Byrne and R. J. Sampson (Eds.), The social ecology of crime (pp. 1-22). New York: Springer-Verlag.

Ceccato, V. (2005) Homicide in São Paulo, Brazil: Assessing spatial-temporal and weather variations. Journal of Environmental Psychology, 25, 307-321.

Ceccato, V., \& Dolmen, L. (2011) Crime in rural Sweden. Applied Geography, 31, 119-135.

Cheatwood, D. (1988) Is there a season for homicide? Criminology, 26, 287-306.

Chenery, S., Holt. J., \& Pease. K. (1997) Biting back II: reducing repeat victimisation in Huddersfield. Home Office Crime Detection and Prevention Series Paper 82. London: Home Office; 1997.

Chikkerur, S., Cartwright, A. N., \& Govindaraju, V. (2007) Fingerprint enhancement using STFT analysis. The Journal of Pattern Recognition, 40, 198-211.

Cohen, L. \& Felson, M. (2006) Social change and crime rates trends: a routine activity approach. American Sociological Review, 44, 588-608.

Cohn, E. G. \& Rotton, J. (2000). Weather, seasonal trends and property crimes in Minneapolis, 1987-1988: A moderator-variable time-series analysis of routine activities. Journal of Environmental Psychology, 20, 257-272.

Cohn, E. G. \& Rotton, J. (2003). Even criminals take a holiday: instrumental and expressive crimes on major and minor holidays. Journal of Criminal Justice, 31, 351-360.

Edelman, G., Manti, V., van Ruth, S. M., van Leeuwen, T., \& Aalders, M. (2012). Identification and age estimation of blood stains on colored backgrounds by near infrared spectroscopy. Forensic Science International, 220, 239-244.

Feldman, H. S. \& Jarmon, R. G. (1979). Factors influencing criminal behavior in Newark: A local study in forensic psychiatry. Journal of Forensic Science, 24, 234-239. 
Felson, M. \& Poulsen, E. (2003). Simple indicators of crime by time of day. International Journal of Forecasting, 19, 595-601.

Field, S. (1992). The effect of temperature on crime. British Journal of Criminology, 3, 340351.

Gould, C., Burger, J., \& Newham, G. (2012). The SAPS crime statistics: What they tell us and what they don't. SA Crime Quarterly, 42, 3-12.

Hakko, H. (2000). Seasonal variation of suicides and homicides in Finland. Unpublished academic thesis, Department of Psychiatry, University of Oulu, Finland.

Henry, L. M., \& Bryan, B. A. (2000). Visualising the spatio-temporal patterns of motor vehicle theft in Adelaide, South Australia. Paper presented at the Australian Institute of Criminology Conference, Adelaide, September 2000.

Hipp, J. R., Bauer, D. J., Curran, P. J., \& Bollen, K. A. (2004). Crimes of opportunity or crimes of emotion? Testing two explanations of seasonal change in crime. Social Forces, 82 , $1333-1372$.

Hird, C. \& Ruparel, C. (2007) Seasonality in recorded crime: preliminary findings. British Home Office Online Report 02/07. Available from: http://webarchive.nationalarchives.gov.uk/20101208185817/http://rds.homeoffice.gov.uk/rds/ pdfs07/rdsolr0207.pdf

Jewkes, R. \& Abrahams, N. (2002). The epidemiology of rape and sexual coercion in South Africa: An overview. Social Science and Medicine, 55, 1231-1244.

Johnson, S. D. (2008). Repeat burglary victimization: A tale of two theories. Journal of Experimental Criminology, 4, 215-240.

Kynoch, G. (2003). Apartheid nostalgia: personal security concerns in South African townships. SA Crime Quarterly, 5, 7-10.

Landau, S.F. \& Fridman, D. (1993). The seasonality of violent crime: The case of robbery and homicide in Israel. Journal of Research in Crime and Delinquency, 30, 163-191.

LeBeau, J. L. (1994). The oscillation of police calls to domestic disputes with time and the temperature humidity index. Journal of Crime and Justice, 17, 149-161. 
LeBeau, J. L. \& Corcoran, W. T. (1990). Changes in calls for police service with changes in routine activities and the arrival and passage of weather fronts. Journal of Quantitative Criminology, 3, 269-291.

LeVeque R. L. \& Trefethen, L. N. (1988). Fourier analysis of the SOR iteration. IMA Journal of Numerical Analysis, 8, 273-279.

McDowall, D., \& Loftin, C. (1992) Comparing the UCR and NCS over time. Criminology, $30,125-132$.

Miller, H. J. (2005). A measurement theory for time geography. Geographical Analysis, 37, $17-45$.

Morrison, S. \& O’Donnell, I. (1994). Armed robbery: A study in London. Occasional paper no. 15. Oxford: Centre for Criminological Research.

Peng, C., Xueming, S., Hongyong, Y., \& Dengsheng, L. (2011). Assessing temporal and weather influences on property crime in Beijing, China. Crime, Law, and Social Change, 55, $1-13$.

Pittman, D. J. \& Handy, W. (1964). Patterns in criminal aggravated assault. Journal of Criminal Law and Criminology, 55, 462-470.

Pokorny, A. D. (1965). A comparison of homicide in two cities. Journal of Criminal Law and Criminology, 56, 479-487.

Polvi, N., Looman, T., Humphries, C., \& Pease, K. (1990) Repeat break-and-enter victimization: time course and crime prevention opportunity. Journal of Police Science and Administration, 17, 8-11.

Quételet, M. A. (1969) A treatise on man and the development of his faculties. New York: Burt Franklin. 
Ratcliffe, J. H. (2006). J H. A temporal constraint theory to explain opportunity-based spatial offending patterns. Journal of Research in Crime and Delinquency, 43, 261-291.

Ratcliffe, J. H. (2010). Aoristic analysis: the spatial interpretation of unspecific temporal events. International Journal of Geographical Information Science, 14, 669-679.

Rengert, G. F. \& Wasilchick, J. (1985). Suburban burglary: a time and place for everything. Springfield, IL: C.C. Thomas.

Rhodes, W., Kling, R., \& Johnston, P. (2007). Using booking data to model drug user arrest rates: A preliminary to estimating the prevalence of chronic drug use. Journal of Quantitative Criminology, 23, 1-22.

Rotton, J. \& Cohn, E. G. (2000). Weather, disorderly conduct, and assaults: from social contact to social avoidance. Environment and Behavior, 32, 651-673.

Shaw, C. \& McKay, H. D. (1942). Juvenile delinquency and urban areas. Chicago: University of Chicago Press.

Sidebottom, A. (2012). Repeat burglary victimization in Malawi and the influence of housing type and area-level affluence. Security Journal, 25, 265-281.

Smart, J. L. (2010). Estimation of time of death with a Fourier series unsteady-state heat transfer model. Journal of Forensic Science, 55, 1481-1487.

South African Police Service (2014). SAPS annual report 2013/14. Available at: http://www.saps.gov.za/about/stratframework/annual_report/2013_2014/ar2014_02_partb.pdf [last accessed 17 March 2016].

Statistics South Africa. (2011). Victims of crime survey 2011. Available at: http://www.statssa.gov.za/publications/P0341/P03412011.pdf [last accessed 6 July 2016].

Stein, E. M. \& Shakarchi, R. (2003). Fourier Analysis: An Introduction. New Jersey: Princeton University Press. 
Sutherland, E. H. (1947). Principles of criminology. Philadelphia, PA: Lippincott.

Tolstov, G. P. (1976). Fourier Series. New Jersey: Prentice Hall.

Townsley, M., Homel, R., \& Chaseling, J. (2000). Repeat burglary victimization: Spatial and temporal patterns. Australian and New Zealand Journal of Criminology, 33, 37-63.

Tranter, P. J. (1985). Intra-urban variability in rhythms of pathological events. Geografiska Annaler. Series B, Human Geography. 67, 7-14.

Van Koppen, P. J. \& Jansen R. W. J. (1999) The time to rob: Variation in time of number of commercial robberies. Journal of Research in Crime and Delinquency, 36, 7-29.

Weisel, D. L. Analyzing repeat victimization. Problem- Oriented Guides for Police ProblemSolving Tools Series No.4. U.S. Washington, DC: Department of Justice.

Whittaker, E.T. \& Robinson, G. (1924). The calculus of observations: A treatise on numerical mathematics. London: Blackie and Son. 